\title{
AmAZGNÁNAS
}

DOI: https://doi.org/10.34069/RA/2020.6.03

Volumen 3, Número 6/julio-diciembre 2020

\section{El proceso de apropiación y concentración de la tierra rural en el departamento Presidencia de la Plaza (Chaco)}

\author{
The process of appropriation and concentration of rural land in the Presidencia \\ de la Plaza department (Chaco)
}

Recibido: 29 de agosto de $2020 \quad$ Aceptado: 30 de octubre de 2020

Autores:

Gerardo Roberto Martínez ${ }^{3}$

\section{Resumen}

El objetivo es mostrar el proceso de posesión de la tierra en el departamento Presidencia de la Plaza, situación similar al de otros departamentos del centro este de la provincia del Chaco (Argentina), analizando la estratificación por superficie y la participación relativa de los diferentes estratos en el total de las explotaciones departamentales. En su elaboración se recurrió a los censos de población y agropecuarios realizados, a material bibliográfico y artículos periodísticos sobre el área estudiada, como también entrevistas a pobladores locales, siendo la misma parte de la investigación doctoral del autor.

Las primeras normas legales favorecían la concentración de la tierra, promoviendo la entrega de grandes extensiones e impidiendo el acceso a los pequeños productores. Hacia finales del siglo XX se vivió un proceso de concentración promovido por el cambio del modelo productivo y, a diferencia de lo ocurrido en otras regiones del Chaco, donde se vivió un proceso de concentración de la tierra por parte de capitales extra provinciales, en Presidencia de la Plaza esto no sucedió así, sino que fue un proceso con mayoritarias características locales. La explicación obedece a que productores que estaban endeudados y que para resolver esa situación necesitaban vender su tierra, a los agentes extra-regionales se les complicaba la adquisición porque alrededor del predio que se ofrecía a la venta tenían productores que no querían vender; la distribución parcelaria impidió el ingreso extra-regional, pero el modo de producción y la estructura del sector se modificaron sustancialmente en comparación con la correspondiente a la etapa algodonera; los que no le pudieron vender a los agronegocios les vendieron a sus vecinos, produciendo en cierta medida un proceso de concentración de la tierra que confirma el efecto Mateo en este sector.

Palabras clave: Departamento Presidencia de la Plaza, Chaco, Territorio, Poblamiento, Ruralidad.

\begin{abstract}
The objective is to show the process of land possession in the Presidencia de la Plaza department, a situation similar to that of other departments in the eastern center of the Chaco province (Argentina), analyzing the stratification by area and the relative participation of the different strata in all departmental farms. In its preparation, the population and agricultural censuses carried out

\footnotetext{
3 Ingeniero agrónomo, Magister en Desarrollo Social, Doctor en Geografía INTA-Jefe Agencia de Extensión Rural San Martín, General José de San Martín (Chaco-Argentina). ORCID: https://orcid.org/0000-0002-5804-6437
} 
were used, as well as bibliographic material and journalistic articles about the studied area, as well as interviews with local inhabitants, being the same part of the author's doctoral research.

The first legal norms favored the concentration of land, promoting the handover of large areas and preventing access to small producers. Towards the end of the 20th century, there was a process of concentration promoted by the change in the production model and, unlike what happened in other regions of the Chaco, where there was a process of concentration of land by extra-provincial capitals, in the Presidencia de la Plaza this did not happen like that, but rather it was a process with the majority local characteristics. The explanation is due to the fact that producers who were in debt and who needed to sell their land in order to resolve that situation, the extra-regional agents found it difficult to acquire because around the property that was offered for sale they had producers who did not want to sell; the parcel distribution prevented extra-regional income, but the mode of production and the structure of the sector were substantially modified compared to that corresponding to the cotton stage; those who could not sell to agribusinesses sold to their neighbors, producing to some extent a process of land concentration that confirms the Mateo effect in this sector.

Keywords: Presidencia de la Plaza department, Chaco, Territory, Population, Rurality.

\section{Introducción}

La investigación se centra en el departamento Presidencia de la Plaza, ubicado en el centro oriental de la provincia argentina de Chaco. Posee una superficie de 228.400 hectáreas, de las cuales 13.000 hectáreas corresponden a suelos con aptitud agrícola con limitaciones ligeras a moderadas para el desarrollo de esta actividad, a esta superficie se suman 17.000 hectáreas donde la agricultura puede desarrollarse con limitaciones severas. Las precipitaciones y su distribución anual, junto con los caracteres topográficos y edáficos, determinan las áreas potenciales para la producción agropecuaria; este departamento es atravesado por la isohieta de $1.100 \mathrm{~mm}$.

El presente trabajo analiza el proceso de apropiación y concentración de la tierra en el departamento Presidencia de la Plaza; atento a que este ha tenido distintas configuraciones departamentales a lo largo del tiempo, solo se podrá realizar una comparación censal en el periodo comprendido entre 1953 a la actualidad, sin embargo, el periodo anterior constituye la base del proceso apropiador, cuyas raíces se registran con mayor fuerza a partir de 1870 , fecha de inicio de la guerra contra los pueblos originarios con el objetivo de quitarles sus tierras y su libertad, aunque esta comenzó en el siglo XVI, con la llegada de los primeros españoles a la región chaqueña austral en 1526.

El objetivo es mostrar el proceso de apropiación de la tierra en el departamento Presidencia de la Plaza, situación similar al de otros departamentos del centro este de la provincia del Chaco, analizando la estratificación por superficie y la participación relativa de los diferentes estratos en el total de las explotaciones departamentales. A diferencia de lo ocurrido en otras regiones de la provincia, donde se vivió un proceso de concentración de la tierra por parte de capitales extra provinciales, en Presidencia de la Plaza esto no sucedió así, sino que fue un proceso con mayoritarias características locales, pero donde igualmente se verifica el efecto Mateo en la apropiación de la tierra (Merton, 1968).

\section{Marco teórico}

Aunque no abundan los trabajos específicos realizados sobre el espacio de estudio, en los últimos años comenzaron a realizarse contribuciones por parte de personas radicadas en el área de estudio que, desde sus formaciones profesionales, roles laborales e intereses heurísticos, aportaron descripciones, análisis e interpretaciones sobre este espacio; entre ellos pueden mencionarse a Russo (1989) sobre condiciones estructurales y funcionales en fincas de 


\section{AMAZONANAS}

agricultores con recursos limitantes, García y Busiello (1997), que se refieren a los orígenes de Presidencia de la Plaza, Martínez (2018) trata aspectos geográficos e históricos del departamento. Asimismo se encuentra cuantiosa información dispersa en disímiles publicaciones, generalmente desarrolladas a escala provincial y regional, entre cuyos autores figuran Miranda (1955), Bruniard (1979), López Piacentini (1979), Beck (1994), Maeder (1996) y Manoiloff (2001; 2008). Igualmente, existen informes técnicos generados en organismos gubernativos que, generalmente, tratan aspectos puntuales, en mayor medida vinculados con los sectores productivos; además, una enorme información histórica se halla desperdigada en distintos archivos de la provincia y en libros históricos de establecimientos escolares.

\section{Materiales y métodos}

Para la elaboración de este trabajo, se recurrió a los censos de población y agropecuarios realizados, a material bibliográfico y artículos periodísticos sobre el área estudiada, como así también entrevistas a pobladores locales, siendo la misma parte de la investigación doctoral del autor. Cabe aclarar que este ha recorrido la zona desde hace tres décadas, lo que le ha permitido conocer el departamento y sus pobladores, compartiendo con ellos sus experiencias de vida, sus historias, conociendo los procesos de poblamiento de los que estos o sus antepasados han sido actores.

\section{Resultados}

\section{El poblamiento}

Cuando en el siglo XVI los españoles toman contacto con las culturas aborígenes del Chaco, el pueblo radicado en el área de Presidencia de la Plaza y alrededores eran los abipones (Dobrizhoffer, 1968), quienes tenazmente resistieron la llegada de los conquistadores, hasta que en el siglo XVII la fuerza española en conjunto con los guaraníes, hizo que debieran emigrar para una nueva localización (Bitus, 2010). Al migrar los abipones, el territorio fue ocupado por los qom hacia el siglo XVIII, empujados por los wichis, que los desalojaron del territorio que ocuparon primeramente: todo el actual territorio de Formosa llegando hasta el territorio ocupado por los chiriguanos en Salta.

Los primeros pobladores no originarios que se internaron en las planicies boscosas del Chaco central pertenecían al ejército, que llevaba adelante la guerra contra la población nativa iniciada en 1870. Estos nuevos habitantes se acantonaban un tiempo en los fortines y, luego, eran trasladados, aunque algunos de ellos se radicaron en el territorio, como es el caso del ex teniente Lionel Fitz Maurice; lo mismo sucedió con algunos obreros del ferrocarril, que se quedaron en la zona cuando las cuadrillas de obreros se retiraban, tales como Francisco De Castro, los hermanos Pedro y José Pérez Ponce, Miguel Pardo, entre otros (Ruíz, 1967; Martínez, 2018).

La ocupación masiva del territorio de Presidencia de la Plaza con población no originaria comenzó a principios del siglo XX, reconociendo dos vertientes; una que llegó desde Santa Fe y Corrientes (inmigración criolla), otra que llegó desde el extranjero o constituida por la primera generación de inmigrantes extranjeros. Aquella inició en la primera década del siglo XX, en tanto que la otra lo hizo en la segunda década.

En 1915, a partir del Decreto de División Departamental de los Territorios Nacionales se creó el departamento IV-Martínez de Hoz, el cual se componía íntegramente por el depar-tamento Presidencia de la Plaza y Sargento Cabral y parte de los departamentos 25 de ma-yo, San Martín y General Donovan. Al momento de realizarse el censo general de los Terri-torios Nacionales (Argentina. Asesoría Letrada de Territorios Nacionales, 1920), el departamento Martínez de Hoz 


\section{AMAZONAS}

registraba una población total de 2.009 habitantes, 859 en el área urbana y 1.150 en la rural (Cuadro $\mathrm{N}^{\mathrm{o}}$ 1).

Cuadro No 1.

Población urbana, rural y total en el departamento Martínez de Hoz. Año 1920.

\begin{tabular}{|l|c|c|c|}
\hline Cuatro Árboles & Población urbana & Población rural & Población total \\
\hline Presidente de la Plaza & - & 109 & 109 \\
\hline Salto de la Vieja & 859 & - & 859 \\
\hline San Carlos & - & 127 & 127 \\
\hline Resto del departamento & - & 73 & 73 \\
\hline Total & - & 841 & 841 \\
\hline
\end{tabular}

Fuente: elaboración propia en base a (Argentina. Asesoría Letrada de Territorios Nacionales, 1920)

\section{El régimen legal}

La política de tierras para los territorios nacionales atravesó diferentes etapas; en principio la adjudicación estuvo regulada por la Ley $\mathrm{N}^{\circ}$ 817/1876 de Inmigración y colonización y su reforma de 1891- y la Ley $\mathrm{N}^{\circ}$ 1.291. Estas leyes regularon la ocupación de tierras en la región este del territorio chaqueño y no tuvieron influencia en la región centro oriental.

Durante la primera mitad del siglo XX el marco legal estuvo definido por las leyes $4.167 / 1903$ y 5.559/1908. La primera tuvo el objetivo de corregir el manejo administrativo de la tierra fiscal, producto de esto se estableció la exploración y la mensura antes de su adjudicación, determinando que las tierras podían ser destinadas a explotación agrícola o ganadera; en el primer caso, los terrenos eran fraccionados en 100 hectáreas, mientras que las áreas pastoriles se dividían en 625 o 2.500 ha (Ley $\mathrm{N}^{\circ} 817,1876$ ). La colonización agrícola se proyectó en las abras altas, con aguas subterráneas potables, mientras que las colonias pastoriles se instalaron en lugares anegadizos, sin otra aplicación que el pastoreo; el otorgamiento podía realizarse por donación, venta directa, arrendamiento o venta en remate; la Ley $\mathrm{N}^{\circ} 5.559$ de Fomento de Territorios Nacionales tenía el objetivo de llevar adelante obras públicas para facilitar el poblamiento del territorio.

La colonización en el Territorio Nacional del Chaco logró un rápido crecimiento durante las presidencias radicales de 1916/1930. En 1921 se promulgó el Decreto No 8.709 a través del cual se hacía oficial la creación de 9 colonias agrícolas, 5 colonias pastoriles y la fundación de 11 pueblos en la zona de influencia del ferrocarril del Estado; a través de este decreto, se fundó oficialmente Presidencia de la Plaza y se creó la colonia pastoril Coronel Brandsen y la colonia agrícola Hipólito Vieytes Esta labor continuó durante la década de 1930 y la pri-mera mitad del '40; para 1950 estaban destinadas para la colonización prácticamente todas las tierras aptas para agricultura y los mejores campos ganaderos.

La tierra destinada al arrendamiento era aquella que reunía condiciones por sus cualidades, por la distancia a centros poblados o a estaciones de los ferrocarriles de fomento y se acor-daba sin derecho a compra, por un término de diez años; las condiciones que debía cumplir el colono para acceder a esta ocupación eran ser de nacionalidad argentina, residir y explotar directamente el lote. La selección del poblador estaba a cargo de la Dirección de Tierras (Almirón, 2010), aunque la presencia cada vez más numerosa de intrusos significó un positivo aporte para el progreso de la gobernación: 


\section{AMAZUNAS}

"Se deduce, pues, que el territorio del Chaco poco debe a los capitalistas que obtuvieron concesiones de tierra con tantas franquicias, facilidades y hasta descuidos y favoritismos por parte del Gobierno, que llegaron a recibir el título de propiedad sin haber cumplido con ninguna de las cláusulas de la ley de colonización que regía entonces" (Muello, 1926).

Provincializado el Chaco en 1952, se sancionó la Ley $\mathrm{N}^{\circ} 16$, que establecía el régimen de tierras fiscales; el 17 de febrero de 1972 se sancionó el Decreto Ley N$^{\circ}$ 1.094, por el cual se creó el Instituto de Colonización, el cual establece en el artículo 20 que:

"Las tierras a colonizar serán divididas a superficies que constituyan unidades económicas de explotación agrícola, ganadera mixta granjera, tambera o especial. Para ella se tendrá en cuenta la naturaleza y amplitud del suelo, los caracteres climáticos, la ubicación y las condiciones económicas, sociales de la zona" (Decreto Ley No 1.094, 1987)

Así dejaba de hablarse de una cantidad fija de tierra según sea destinado para agricultura o ganadería, tal como era dispuesto por la ley nacional 4.167/1903. El 28 de enero de 1977 fue sancionado el Decreto Ley $\mathrm{N}^{\mathrm{o}} 2.040$, un nuevo régimen de tierras fiscales que en su apartado número 3, bajo el título "los Intrusos" -categoría histórica de fines del siglo XIX-, establecía que "cualquier ocupante de tierras fiscales sin la debida autorización del Instituto de Colonización, será considerado intruso a los fines de la presente ley” (Bageneta, 2015, pág. 173).

La Ley $\mathrm{N}^{\circ} 2.822$ se refiere a la adjudicación de predios por parte del Instituto de Colonización y tuvo sanción el 8 de junio de 1983; la Ley $\mathrm{N}^{\mathrm{o}}$ 2.913/1984 es la que actualmente rige el régimen de tierras fiscales en la provincia.

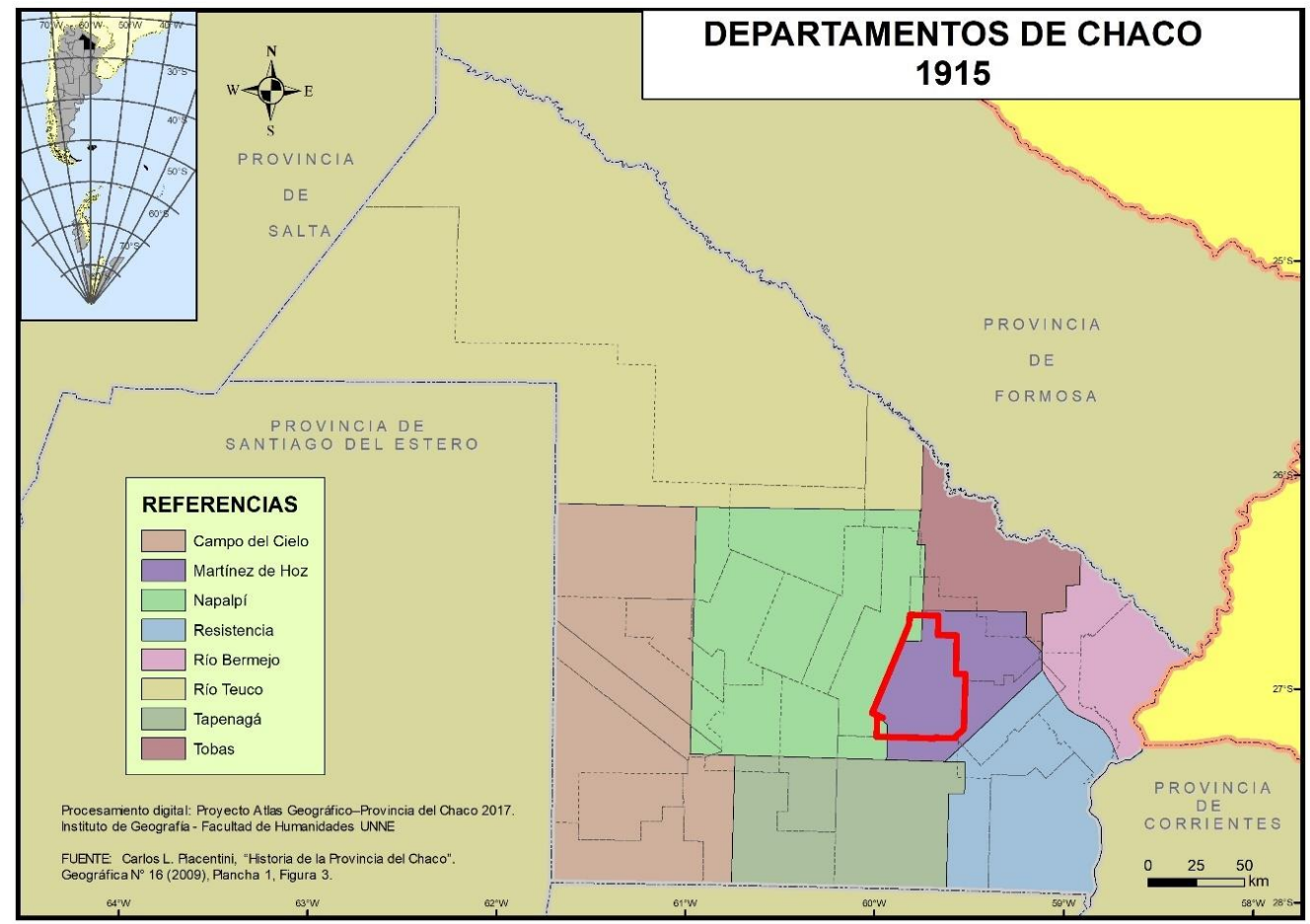

Ilustración 1. Ubicación del departamento Presidencia de la Plaza y configuración departamental de 1915. 


\section{AMAZUNANAS}

\section{Estructura parcelaria}

Esta estructura refleja la evolución del proceso de apropiación de la tierra manifestada en la provincia, en coincidencia con las fases de expansión de las actividades forestal y algodonera. Al momento de realizarse el Censo Algodonero de la República Argentina en los años 1935/36, la distribución de la tenencia de la tierra en el departamento Martínez de Hoz se refleja en el Cuadro $\mathrm{N}^{\mathrm{o}} 2$.

\section{Cuadro No 2.}

Tipo de tenencia, cantidad de chacras y superficie cultivada en el departamento Martínez de Hoz.

\begin{tabular}{|l|r|r|r|r|}
\multicolumn{2}{|c|}{ Tipo de tenencia } & \multicolumn{2}{c|}{$\begin{array}{c}\text { Cantidad de } \\
\text { chacras }\end{array}$} & \multicolumn{3}{c|}{$\begin{array}{c}\text { Superficie cultivada } \\
\text { (has.) }\end{array}$} & $\begin{array}{c}\text { Promedio cultivado } \\
\text { (has.) }\end{array}$ \\
\hline Propietarios & 7 & 1,7 & 375 & 53 \\
\hline Arrendatarios & 23 & 5,7 & 464 & 20 \\
\hline Ocupantes & 375 & 92,6 & 7.731 & 20 \\
\hline Total: & $\mathbf{4 0 5}$ & $\mathbf{1 0 0}$ & $\mathbf{8 . 5 7 0}$ & $\mathbf{2 1}$ \\
\hline
\end{tabular}

Fuente: (República Argentina - Ministerio de Agricultura, Junta Nacional del Algodón, 1936, pág. 90).

El proceso de ocupación del territorio en Presidencia de la Plaza no estuvo exento de apremios, originándose conflictos entre ganaderos y agricultores por la utilización de la tierra, trayendo como consecuencia disputas que costaron la vida a más de un poblador (Pellegrino \& Franco de García, 2014); en 1934 se produjeron 9 homicidios en Presidencia de la Plaza (Castells, 1936), la mayoría vinculados a problemas territoriales; en el mismo período se produjo el mismo número de hurtos.

Cuando se comenzó a mensurar y entregar tierras en el departamento, se respetaba o hacía prevalecer un supuesto derecho de sectores con mayor poder, no así el de primitivos pobladores -derrotados militarmente- o el de pequeños productores que, afincados en la tierra, la trabajaban para sobrevivir. Esto provocó otra serie de conflictos que originaron la expulsión de pobladores del campo:

"Las colonias eran grandes porque las tierras eran fiscales, cuando se comenzó a lotear la gente no pudo comprar y los que compraban echaban a los ocupantes" (Barrios \& Blanco, 2012).

Se advierte la distinta lógica que tenía el descendiente de inmigrantes respecto del descendiente de campesinos correntinos:

"Un día vino González, el de tierra y me preguntó si yo me arreglaba con las 17 hectáreas de tierra que me dejó mi papá. Y le dije que sí, cuando podría haber pedido 50 hectáreas, si yo soy nacido y criado en el cinco, me tenían que dar" (Alarcón, 2013).

"Mi viejo trabajaba con Foschiatti veinte años, cuando vinieron de Tierras para decirle que se iba a lotear el lote de 100 hectáreas que era de Foschiatti y que él tenía derecho a solicitar una parcela porque hacía más de veinte años que estaba allí, mi viejo dijo que no quería nada" (Obregón, 2015).

Otra práctica utilizada por quienes pretendían acceder a la propiedad de la tierra, era el de hacer firmar a los ocupantes (generalmente analfabetos) un acuerdo por el cual se les respe- 


\section{AMAZONAS}

taría que permanecieran en el lugar mientras vivieran, sin ser molestados. Estos acuerdos carecían de valor al momento de ser transferidas las propiedades:

"En 1952 ocupé la tierra donde vivo y de donde ahora me quieren desalojar. Soy inocente para que me hagan estas cosas. Vino el jefe de tierra con LB que fue el que solicitó la tierra y firmé un acuerdo con don LB por el que podría ocupar el lugar donde estaba mientras viviera" (Talavera, 2015).

El censo de 1947 (Cuadro $\mathrm{N}^{\circ}$ 3) indicaba la existencia de 1.287 establecimientos agropecuarios (EAP) contra 405 registrados en 1936; la variación en la cantidad de EAP entre ambos censos obedece a que el primero solamente contabilizaba los establecimientos cultivados con algodón, en tanto que el segundo lo hacía sobre el total.

\section{Cuadro No 3.}

Cantidad y superficie de las EAP clasificadas por tipo de tenencia, explotaciones y hectáreas en el departamento Martínez de Hoz.

\begin{tabular}{|l|c|c|}
\hline \multicolumn{1}{|c|}{ Tipo de tenencia } & Cantidad EAP & Superficie (ha) \\
\hline Propietario & 80 & 117.943 \\
\hline Arrendatario & 211 & 21.762 \\
\hline Mediero y tantero & 14 & 168 \\
\hline Ocupante gratuito & 42 & 41.418 \\
\hline Tierras fiscales & 898 & 139.353 \\
\hline Propietario o arrendatario & 6 & 6.477 \\
\hline Propietario y ocupantes gratuitos & 1 & 2.500 \\
\hline Propietario y tierras fiscales & 5 & 428 \\
\hline Otras formas y sin determinar & 30 & 27.267 \\
\hline Total & $\mathbf{1 . 2 8 7}$ & $\mathbf{3 5 7 . 3 1 6}$ \\
\hline
\end{tabular}

Fuente: (Argentina. Ministerio de Asuntos Técnicos, 1947).

En 1947, el 80\% de los EAP poseían menos de 75 hectáreas, destacando que casi el 63\% contaban con menos de 25 hectáreas (Cuadro $\mathrm{N}^{\circ}$ 4); esta situación obedecía al perfil pr-ductivo del departamento Martínez de Hoz, donde el cultivo predominante era el algodón, muy exigente en mano de obra, ya que demandaba dos personas por hectárea sembrada (República Argentina Ministerio de Agricultura, Junta Nacional del Algodón, 1936, pág. 88) y, asimismo, era el que mayor retribución otorgaba a la familia. El mismo censo mencionaba la existencia de 1.072 establecimientos cultivados con algodón, totalizando 13.457 hectáreas. 
Cuadro $\mathbf{N}^{\circ} 4$.

Estratificación de las EAP en el departamento Martínez de Hoz.

\begin{tabular}{|c|c|c|c|}
\hline Estrato & Cantidad EAP & Porcentaje & Porcentaje acumulado \\
\hline 0,1 a 5 & 250 & $19,43 \%$ & $19,43 \%$ \\
\hline 5,1 a 10 & 240 & $18,65 \%$ & $38,07 \%$ \\
\hline 10,5 a 25 & 316 & $24,55 \%$ & $62,63 \%$ \\
\hline 25,1 a 50 & 178 & $13,83 \%$ & $76,46 \%$ \\
\hline 50,1 a 75 & 46 & $3,57 \%$ & $80,03 \%$ \\
\hline 75,1 a 100 & 64 & $4,97 \%$ & $85,00 \%$ \\
\hline 100,1 a 150 & 22 & $1,71 \%$ & $86,71 \%$ \\
\hline 150,1 a 200 & 9 & $0,70 \%$ & $87,41 \%$ \\
\hline 200,1 a 250 & 4 & $0,31 \%$ & $87,72 \%$ \\
\hline 250,1 a 300 & 5 & $0,39 \%$ & $88,11 \%$ \\
\hline 300,1 a 500 & 16 & $1,24 \%$ & $89,36 \%$ \\
\hline 500,1 a 750 & 29 & $2,25 \%$ & $91,61 \%$ \\
\hline 750,1 a 1.000 & 7 & $0,54 \%$ & $92,15 \%$ \\
\hline $1.000,1$ a 2.000 & 65 & $5,05 \%$ & $97,20 \%$ \\
\hline $2.000,1$ a 4.000 & 0 & $0,00 \%$ & $97,20 \%$ \\
\hline $4.000,1$ a 5.000 & 7 & $0,54 \%$ & $97,75 \%$ \\
\hline $5.000,1$ a 7.500 & 1 & $0,08 \%$ & $97,82 \%$ \\
\hline $7.500,1$ a 10.000 & 8 & $0,62 \%$ & $98,45 \%$ \\
\hline $10.000,1$ a 20.000 & 0 & $0,00 \%$ & $98,45 \%$ \\
\hline $20.000,1$ a 30.001 & 0 & $0,00 \%$ & $98,45 \%$ \\
\hline $30.000,1$ a 40.000 & 1 & $0,08 \%$ & $98,52 \%$ \\
\hline Campo abierto & 10 & $0,78 \%$ & $99,30 \%$ \\
\hline Sin determinar & 9 & $0,70 \%$ & $100,00 \%$ \\
\hline Total: & 1.287 & $100 \%$ & \\
\hline
\end{tabular}

Fuente: elaboración propia en base a (Argentina. Ministerio de Asuntos Técnicos, 1947)

Los descendientes de inmigrantes, con una lógica productiva de maximización de ganancias, tomaron la mayor cantidad de tierras que les estaba permitido, en tanto los correntinos, con una lógica asociada al buen vivir, solo tomaron aquello que iban a trabajar, que les permitía reproducirse pero sin ánimo de acumular, siguiendo lo expresado por Chayanov respecto que el campesino trabaja hasta satisfacer sus necesidades (Chayanov, (1925) 1985), por lo que podría decirse que "deja de trabajar para poder vivir".

Los ganaderos, provenientes de Santa Fe, ocuparon con sus ganados las tierras que habían sido despobladas por la acción militar previa (proceso de desterritorialización), pero con el paso del tiempo y el advenimiento de la agricultura, generó conflictos entre ganaderos y agricultores. Ello dio paso a una nueva configuración departamental, ubicándose los agricultores al norte de las vías del ferrocarril (suelos altos, predominantemente) y los ganaderos lo hicieron al sur de la vía, en suelos mayormente bajos.

La ocupación del territorio por "intrusos" se fue dando en forma anárquica, excepto Colonia Vieytes, que fue mensurada en lotes de 100 hectáreas; esta ocupación territorial motivó que la población de cada colonia o paraje fuera diferente, notándose que aquellas zonas habitadas por pequeños productores tuvieron más vida: pistas de baile, almacenes y canchas de fútbol estaban ubicadas donde había mucha población campesina. 


\section{AMAZONAS}

\section{Explotaciones agropecuarias}

El proceso de apropiación de la tierra en el Chaco y en Presidencia de la Plaza no estuvo separado del proceso que sobre el mismo aspecto se vivió a nivel nacional. Fueron políticas explicitas, tal como las que definió el Ing. Ingaramo, miembro del equipo de Domingo Felipe Cavallo, quien señalara en 1990 que en la Argentina debían desaparecer 200.000 productores por ineficientes. Incluso, al retrotraerse en el tiempo, desde el decreto-ley Raggio ${ }^{4}$-promulgado en 1967 durante la presidencia de Onganía y que terminó con los arrendatarios estables-, hasta el 2001 se perdieron 250.000 pequeños productores en todo el país (Barrado, 2006). En 2002 existían 333.533 EAP en el territorio nacional; en 2008, esa cifra cayó un $18 \%$ y se redujo a 273.590 (Mangione \& Marenco, 014). En el Chaco se pasó de 26.853 EAP en 1960 a 15.740 en 2008 (INDEC, 2008); esto representó una pérdida de 11.113 establecimientos menos (-41\%) en el periodo de casi medio siglo; en Presidencia de la Plaza existían 929 EAP en 1960, que se redujeron a 396 en 2008 (INDEC, 2008).

\section{Ilustración 2.}

Evolución histórica de los EAP en el periodo 1960/2008, por estrato de superficie en el departamento Presidencia de la Plaza.



Fuente: elaboración propia en base a censos nacionales.

El CNA 2008 relevaba 396 EAP con limites definidos, con un total de 198.444 hectáreas, no indicándose EAP con limites sin definir (INDEC, 2008); con respecto al censo de 1960, representa una pérdida de 533 establecimientos (-57\%).

El estrato menor a 5 hectáreas experimentó un leve incremento en el periodo 1960/09, pero luego acompañó la pérdida que sufrió el estrato de 5,1-25 hectáreas, el cual ya había comenzado su caída en 1960, al igual que el estrato de 25,1-100 hectáreas, que fue perdiendo establecimientos hasta 2008, cuando tuvo un incremento. El estrato de 200,1-500 hectáreas fue incrementándose, con una leve caída en 2001 pero luego recuperado en 2008, en tanto que el estrato $1.000,1$ a 2.500 aumentó en el periodo intercensal 1960/69, cayendo en los dos periodos siguientes y recuperándose en 2001/08. Los estratos de 100,1-200; 500,1-1.000 y 2.500,1-5.000 fueron incrementando paulatinamente la cantidad de establecimientos.

\footnotetext{
${ }^{4}$ Ministro de Agricultura durante el gobierno del presidente de facto Juan Carlos Onganía.
} 
El Cuadro $\mathrm{N}^{\mathrm{o}} 5$ muestra la estratificación de las EAP por superficie y la participación relativa de los diferentes estratos en el total de las explotaciones y de la superficie del departamento en 2008.

Cuadro $\mathbf{N}^{\circ} 5$.

Estructura parcelaria en 2008 en el departamento Presidencia de la Plaza.

\begin{tabular}{|c|c|c|c|c|c|c|}
\hline \multirow[t]{2}{*}{ Estratos } & \multicolumn{3}{|c|}{ EAP } & \multicolumn{3}{|c|}{ Superficie } \\
\hline & Cantidad & $\%$ & Acumulado & Cantidad & $\%$ & Acumulado \\
\hline 0,1 a 5 & 18 & $4,55 \%$ & $4,55 \%$ & 65,5 & $0,03 \%$ & $0,03 \%$ \\
\hline 5,1 a 10 & 15 & $3,79 \%$ & $8,33 \%$ & 128,5 & $0,06 \%$ & $0,10 \%$ \\
\hline 10,1 a 25 & 46 & $11,62 \%$ & $19,95 \%$ & 841,5 & $0,42 \%$ & $0,52 \%$ \\
\hline 25,1 a 50 & 58 & $14,65 \%$ & $34,60 \%$ & $2.332,0$ & $1,18 \%$ & $1,70 \%$ \\
\hline 50,1 a 100 & 63 & $15,91 \%$ & $50,51 \%$ & $4.863,0$ & $2,45 \%$ & $4,15 \%$ \\
\hline 100,1 a 200 & 46 & $11,62 \%$ & $62,12 \%$ & $6.674,5$ & $3,36 \%$ & $7,51 \%$ \\
\hline 200,1 a 500 & 56 & $14,14 \%$ & $76,26 \%$ & $17.655,0$ & $8,90 \%$ & $16,41 \%$ \\
\hline 500,1 a 1.000 & 48 & $12,12 \%$ & $88,38 \%$ & $34.184,0$ & $17,23 \%$ & $33,63 \%$ \\
\hline $\begin{array}{ll}1.000,1 & \text { a } \\
2.500 & \end{array}$ & 27 & $6,82 \%$ & $95,20 \%$ & $41.232,0$ & $20,78 \%$ & $54,41 \%$ \\
\hline $\begin{array}{l}2.500,1 \\
5.000\end{array}$ & 14 & $3,54 \%$ & $98,74 \%$ & $52.804,0$ & $26,61 \%$ & $81,02 \%$ \\
\hline Más de 5.000 & 5 & $1,26 \%$ & $100,00 \%$ & $37.664,0$ & $18,98 \%$ & $100,00 \%$ \\
\hline TOTAL: & 396 & $100,00 \%$ & & $198.444,0$ & $100,00 \%$ & \\
\hline
\end{tabular}

Fuente: elaboración propia, con datos de (INDEC, 2008).

Los datos del Cuadro $\mathrm{N}^{\circ} 5$ permiten constatar que el $76 \%$ de las explotaciones (302) contaban con menos de 500 hectáreas, aspecto que resalta la importancia de los sistemas vinculados con la pequeña y mediana producción agropecuaria al iniciarse el siglo XXI; estas unidades concentraban 17.655 hectáreas y representaban el 16\% de la superficie total incorporada a las explotaciones agropecuarias con límites definidos. Dentro de este grupo resalta la participación de las explotaciones de hasta 50 hectáreas que representan el 34,6\% del total (137 explotaciones) y reúnen el $1,70 \%$ de la superficie (2.332 hectáreas).

El Cuadro $\mathrm{N}^{\circ} 6$ muestra la evolución de la cantidad de EAP en el período intercensal 1960-2008 y la variación absoluta y relativa registrada en los estratos de superficie.

Cuadro $\mathbf{N}^{\circ} 6$.

Variación en las EAP en el período intercensal 1960-2008 en el departamento Presidencia de la Plaza.

\begin{tabular}{|l|r|r|r|r|r|r|r|r|}
\hline & 1960 & 1969 & 1988 & 2001 & 2008 & \multicolumn{2}{c}{ Variación } & \multicolumn{2}{c|}{$\begin{array}{l}\text { VAriación } \\
\text { porcentual }\end{array}$} \\
\hline $\mathbf{0 , 1}$ a 5 & 194 & 203 & 73 & 23 & 18 & -176 & $-91 \%$ \\
\hline $\mathbf{5 , 1}$ a 25 & 365 & 260 & 172 & 74 & 61 & -304 & $-83 \%$ \\
\hline $\mathbf{2 5 , 1}$ a 100 & 251 & 209 & 139 & 103 & 121 & -130 & $-52 \%$ \\
\hline $\mathbf{1 0 0 , 1}$ a 200 & 31 & 55 & 60 & 41 & 46 & 15 & $48 \%$ \\
\hline $\mathbf{2 0 0 , 1}$ a 500 & 10 & 29 & 52 & 47 & 56 & 46 & $460 \%$ \\
\hline $\mathbf{5 0 0 , 1}$ a 1.000 & 30 & 37 & 43 & 44 & 48 & 18 & $60 \%$ \\
\hline $\mathbf{1 . 0 0 0 , 1}$ a 2.500 & 29 & 43 & 30 & 19 & 27 & -2 & $-7 \%$ \\
\hline $\mathbf{2 . 5 0 0 , 1 ~ a ~ 5 . 0 0 0}$ & 7 & 8 & 8 & 11 & 14 & 7 & $100 \%$ \\
\hline
\end{tabular}




\begin{tabular}{|l|r|r|r|r|r|r|r|}
\hline $\begin{array}{l}\mathbf{5 . 0 0 0 , 1} \text { a } \\
\mathbf{1 0 . 0 0 0}\end{array}$ & 2 & 0 & 6 & 5 & 5 & 3 & $150 \%$ \\
\hline Más de 10.001 & 1 & 0 & 0 & 0 & 0 & -1 & $-100 \%$ \\
\hline $\begin{array}{l}\text { Sin } \\
\text { determinar }\end{array}$ & 9 & 0 & 0 & 0 & 0 & -9 & $-100 \%$ \\
\hline Total: & $\mathbf{9 2 9}$ & $\mathbf{8 4 4}$ & $\mathbf{5 8 3}$ & $\mathbf{3 6 7}$ & $\mathbf{3 9 6}$ & $\mathbf{- 5 3 3}$ & $\mathbf{- 5 7 \%}$ \\
\hline
\end{tabular}

Fuente: elaboración propia en base a censos nacionales.

Los datos del Cuadro $\mathrm{N}^{\circ} 7$ permiten inferir que el descenso más significativo en la cantidad de EAP a lo largo de casi medio siglo, se produjo en el estrato de 0,1 a 5 hectáreas (-176 explotaciones), seguido por el estrato de 5,1 a 25 hectáreas (-304 explotaciones); la variación es menor a medida que aumenta el tamaño de las EAP. El estrato que mayor aumento registró en cantidad de EAP fue el comprendido entre 200,1 a 500 hectáreas (+460\%).

Si la comparación se efectúa con el total de EAP con límites definidos existentes en los años 1960 y 2008, el estrato con menos de 100 hectáreas ha disminuido su participación absoluta del $87 \%$ al $51 \%$, pasando de 810 a 200 EAP, expresando una variación de $-75 \%$. En el estrato de más de 100 hectáreas, la participación pasó del $9 \%$ al 38\%, registrándose un aumento en el número de EAP de 71 unidades.

\section{Discusión de resultados}

En relación con los departamentos vecinos, Presidencia de la Plaza es el que registró el mayor descenso en las EAP (-157) en el estrato de menos de 200 hectáreas, por encima de General Donovan y Sargento Cabral, que también registraron pérdidas de EAP (Martínez, 2018).

A diferencia de lo ocurrido en otros departamentos de la provincia, donde se vivió un proceso de concentración de la tierra por parte de capitales extra provinciales, en Presidencia de la Plaza esto no sucedió así, sino que fue un proceso con mayoritarias características locales. En los casos de productores que debido a malas campañas se encontraban endeudados, incluso con entidades crediticias, para resolver esa situación necesitaban vender sus tierras a precios más baratos que el valor real de la misma. A los agentes extra-regionales se les complicaba la adquisición porque alrededor del predio que se ofrecía a la venta, existían productores sin intención de vender. Es de imaginar que un agro negocio que quería incorporarse a la zona debía adquirir una importante cantidad de EAP para lograr acceder a 2.000 hectáreas aproximadamente; en definitiva, estas situaciones permitieron que en el centro-este del Chaco la reconfiguración de los productores se diera a través de una mecánica de adquisición de tierras por parte de vecinos con cierta capacidad de compra, práctica que funcionó de barrera para grandes empresas agropecuarias, frenando su ingreso masivo en el departamento. La distribución parcelaria impidió el ingreso de los actores-extra regionales, pero el modo de producción y la estructura del sector se modificaron sustancialmente en comparación con la que regía durante la etapa de predominio del algodón (1930-1960); al no poderles vender a los agro negocios y sí a ciertos actores locales, se fue produciendo -en cierta medida- un proceso de concentración de la tierra. Los que no vendieron y tenían muy poca tierra, decidieron alquilar a un vecino innovador y exitoso que se animó a invertir en el campo con rindes y ganancias superiores, dedicándose a la ganadería, en comparación con los que optaron por seguir cultivando algodón (Sacchi \& Martínez, 2016).

Esto coincide con Paruelo y Oesterheld, quienes observaron que el aumento en el área sembrada con soja fue mayor en los departamentos que tuvieron menor proporción de superficie departamental ocupada por pequeños productores (menos de 100 has) (Paruelo \& Oesterheld, 2004). 
En el proceso de apropiación de la tierra se observa cómo las geometrías del poder, descriptas por Doreen Massey (2007), actuaron para dar forma a la territorialidad placeña; poderes que actuaron tanto desde el interior como desde el exterior del territorio. En la construcción de los territorios intervienen agentes con diferentes niveles de poder político, económico, social, cultural y simbólico, quienes se enfrentan o se alían para construir aquello que favorece a sus propios intereses y, justamente, es esa la instancia en la que aparece el Estado; es este Estado el que actuó, bajo el gobierno que lo administraba y que respondía a los intereses del grupo dominante, el que hizo que el territorio fuera construido en la forma en que se lo construyó.

A lo largo de la historia del territorio chaqueño, en este caso particular del departamento Presidencia de la Plaza, se ve como la intervención del Estado estuvo presente en esa construcción; un Estado gobernado por un sector de la sociedad que miraba la realidad desde el pedestal victorioso de las luchas independentistas y de las guerras intestinas, pedestal que hacía ver la realidad desde la concepción dominante de quien dirigía los resortes estatales, con ideas que se habían fortalecido a lo largo del tiempo y que traía como colación el efecto Mateo (Merton, 1968) en la concentración de la tierra, donde "a cualquiera que tiene, se le dará, y tendrá más; pero al que no tiene, aun lo que tiene le será quitado" (Mateo, 13:12).

\section{Conclusiones}

Se analizó en este trabajo el proceso de apropiación de la tierra en Presidencia de la Plaza a lo largo de poco más de un siglo, determinando una configuración territorial; en consecuencia, el territorio es una construcción humana, una construcción política y social de apropiación de la naturaleza, cuyas expresiones espaciales se derivan de un legado histórico y, en tanto construcción social, se visibilizan en un entramado de relaciones en constante reconfiguración.

El despoblamiento territorial estuvo impulsado por las crisis que afectaron al algodón, pero hubo también decisiones políticas, explicitas o implícitas que empujaban a los habitantes del campo a irse a la ciudad. En el proceso de territorialización el campesinado, siendo mayoritario, no supo capitalizar el poder político que podía desplegar; esta actitud pasiva los llevó a estar subordinados a sectores con mayor poder político o económico. La territorialidad colectiva se logra con agrupamiento de productores; Alain Touraine sostiene que en América Latina el campesinado, por sí solo, no fue nunca un factor de cambio, solo lo fue cuando estuvo aliado a otros sectores.

Así como antaño hubo un Estado que promovió el afincamiento de un tipo de población expulsando a otro, hoy sucede algo similar; para revertir esta situación son necesarias políticas impulsadas por el Estado con participación ciudadana, para lograr vivir/construir una sociedad que cada día se parezca más a los sueños de sus pobladores, recuperando la capacidad de soñar un futuro mejor para los más postergados.

\section{Declaración de conflicto de interés}

El autor declara que no tienen ningún conflicto de interés.

\section{Bibliografía}

Alarcón, P. P. (2013). Entrevista personal. Entrevistado por G. R. Martínez, Lote V - Colonia Pastoril (Departamento Presidencia de la Plaza), Chaco, Argentina.

Almirón, A. A. (16 de septiembre de 2010). Colonización y Distribución de la tierra en el Territorio del Chaco. Monografia. Recuperado el 4 de noviembre de 2016, de https://www.monografias.com/trabajos82/colonizacion-distribucion-tierra-territorioChaco/colonizacion-distribucion-tierra-territorio-Chaco2.shtml 


\section{AMAZÉNAS}

Argentina. Asesoría Letrada de Territorios Nacionales. (1920). Censo general de los Territorios Nacionales (Vol. I). Buenos Aires, Argentina: Establecimiento Gráfico A. de Martino.

Argentina. Ministerio de Asuntos Técnicos. (1947). IV Censo General de la Nación (Vol. II Censo Agropecuario). Buenos Aires, Argentina: Dirección General del Servicio Estadístico.

Bageneta, J. M. (2015). Del algodón a la soja. Territorios, actores y cooperativas en el Gran Chaco Argentino (1960 - 2010) ( $1^{\mathrm{a}}$ ed.). Buenos Aires, CABA, Argentina: Intercoop.

Barrado, E. M. (2006). Sociedad Rural "Argentina". Zona Económica. Recuperado el 8 de octubre de 2017, http://www.zonaeconomica.com/argentina/sociedadrural

Barrios, F. M., \& Blanco, M. (2012). Entrevista personal, entrevistado por G. R. Martínez, Colonia Brandsen (Departamento Presidencia de la Plaza), Chaco, Argentina.

Bitus, R. (2010). Abipones. Globedia. Recuperado el 28 de febrero de 2014, de http://ar.globedia.com/abipones

Bruniard, E. (1979). El Gran Chaco Argentino. Revista Geográfica (4).

Castells, J. C. (1936). Memoria presentada al Superior Gobierno de la Nación: Año 1934. Corrientes, Corrientes, Argentina: El Liberal.

Chayanov, A. V. ((1925) 1985). La organización de la unidad económica campesina. Buenos Aires, Argentina: Nueva Visión.

Decreto Ley No 1.094. Resistencia. Provincia del Chaco, Argentina. 17 de febrero de 1972

Dobrizhoffer, M. (1968). Historia de los Abipones (Vol. 3). Resistencia, Chaco, Argentina: Facultad de Humanidades - UNNE.

INDEC. (2008). Censo Nacional Agropecuario 2008. Recuperado el 8 de octubre de 2017. http://www.indec.gob.ar/nivel4_default.asp?id_tema_1=3\&id_tema_2=8\&id_tema_3=8 7

Ley N ${ }^{\circ}$ 817. Inmigración y Colonización. República Argentina - Congreso Nacional de Buenos Aires, Argentina. 19 de octubre de 1876

Mangione, G., \& Marenco, L. (2014). Más soja, menos productores. Brújulacomunicacion.com. Recuperado el 8 de octubre de 2017, de: http://brujulacomunicacion.com/index.php/cooperativa/periodico-sursuelo/item/802mas-soja-menos-productores

Martínez, G. R. (2018). La dinámica socio-territorial en el centro-este chaqueño desde finales del siglo XIX hasta principios del siglo XXI. INTA. Recuperado el 25 de octubre de 2018. https://inta.gob.ar/documentos/la-dinamica-socio-territorial-en-el-centro-este-chaquenodesde-finales-del-siglo-xix-hasta-principios-del-siglo-xxi

Massey, D. (2007). Geometrías del poder y la conceptualización del espacio. Conferencia dictada en la Universidad Central de Venezuela, Caracas, 17 de setiembre de 2007. Recuperado el 6 de noviembre de 2020. https://ecumenico.org/geometrias-del-poder-y-laconceptualizacion-del-es/

Merton, R. K. (1968,). The Matthew Effect in Science. Science, 159(3810), 56-63.

Miranda, G. A. (1955). Tres ciclos chaqueños (Crónica histórica regional). Santa Fe, Santa Fe, Argentina: Norte Argentino.

Muello, A. C. (1926). Geografía económica del Chaco y Formosa. Buenos Aires, Argentina: Gráfico Océana.

Obregón, R. R. (2015). Entrevista personal. entrevistado por G. R. Martínez, Lote V - Presidencia de la Plaza, Chaco, Argentina.

Paruelo, J. M., \& Oesterheld, M. (2004). Patrones espaciales y temporales de la expansión de Soja en Argentina. Relación con factores socio-económicos y ambientales. Facultad de Agronomía. Universidad de Buenos Aires, Laboratorio de Análisis Regional y Teledetección, Buenos Aires.

Pellegrino, J. A., \& Franco de García, M. B. (2014). Libro histórico de la Escuela No 183. (C. C. Ferrari Usandizaga, Recopilador) Presidencia de la Plaza. Chaco, Argentina: Mimeo.

República Argentina - Ministerio de Agricultura, Junta Nacional del Algodón. (1936). Censo Algodonero de la República Argentina Año 1935 - 36. Buenos Aires, Argentina: Imprenta López. 
Ruíz, P. A. (1967). Algunas referencias sobre Presidencia de la Plaza y la Escuela Nacional No 58. Presidencia de la Plaza. Chaco, Argentina: Mimeo.

Russo, J. L. (1989). Condiciones estructurales y funcionales en explotaciones (fincas) de agricultores con recursos limitantes del Chaco - Argentina. Tesis de Maestría, CATIE, Turrialba.

Sacchi, P., \& Martínez, G. R. (2016). Territorios rurales del Centro de la Provincia del Chaco. Departamento comandante Fernández. Periodo: 1988-2008. Santiago del Estero: PreALASRU.

Talavera, J. E. (2015). Entrevista personal. Entrevistado por G. R. Martínez, Lote III - Presidencia de la Plaza, Chaco, Argentina. 